East African Medical Journal Vol. 86 (Supplement) December 2009

CLINICAL APPLICATION OF TUMOUR MARKERS: A REVIEW

A. A. Amayo, MBChB, MMed (Path), Senior Lecturer and J.G. Kuria, MBChB, MMed (Path), Lecturer, Department of Human Pathology, College of Health Sciences, University of Nairobi, P. O. Box 19676-00202, Nairobi, Kenya

Request for reprints to: Dr. A. A. Amayo, Department of Human Pathology, College of Health Sciences, University of Nairobi, P. O. Box 19676 - 00202, Nairobi, Kenya

\title{
CLINICAL APPLICATION OF TUMOUR MARKERS: A REVIEW
}

\author{
A. A. AMAYO and J. G. KURIA
}

\begin{abstract}
Background: Tumour markers have made a difference to oncology practice. They can be used in screening, diagnosis, prognostication and assessment of treatment efficacy. Reports on tumour marker usage suggest that many clinicians assume that a biomarker for a particular cancer can be effectively used for all these indications. This assumption is incorrect. Several guidelines have been published to inform clinicians on effective utilisation of these tests.

Objective: To outline the recommended uses of the most commonly requested tumours markers in clinical practice.

Design: A hand search of literature on the recommended use of carcinoembryonic antigen (CEA), alphafetoprotein (AFP), prostate specific antigen (PSA), CA-125 and CA-19.9. Systematic reviews and prospective randomised clinical trials of tumour marker applications were also looked at.

Data sources: Five key journals and reference lists of relevant studies were considered.

Data extraction and synthesis: Two authors abstracted relevant data independently. Emphasis was given to guidelines from expert panels. The quality of the guidelines was assessed by availability of level of evidence supporting the recommendations. Results: Several national and international expert groups have developed guidelines for use of markers for most cancers. CEA, AFP, PSA, CA-125 and CA-19.9 are validated for use in treatment monitoring of colorectal, hepatocellular, prostatic, ovarian and pancreatic carcinomas respectively. AFP and PSA are also useful for cancer screening in high risk groups. CA-125 has limited role in screening while CEA and CA 19.9 are not recommended for cancer screening.

Conclusions: Not all currently available tumour markers can be used for screening and diagnosis of malignancies. Adherence to recommendations on tumour marker utilisation will improve the cost-effectiveness of these tests.
\end{abstract}

\section{INTRODUCTION}

Tumour markers are substances found in tumour cells or body fluids. They are produced by the tumour, or the host in response to the presence of the tumour and can be used to differentiate tumour from normal tissue or determine the presence of a tumour (1-3). Since the first tumour marker was described in 1846 by Henry Bence-Jones (2), numerous tumour markers have been reported in literature for clinical use. A recent report indicated that in the UK about 15 million measurements for tumour markers are done each year (1). The reasons for ordering tumour markers vary considerably and often seems to be inappropriate (4-6). An audit from a hospital in Greece indicated that only $10 \%$ of the requests for tumour markers were appropriate. Notably, $26 \%$ of requests for the ovarian cancer marker CA125, were done for male patients (4). Tumour marker tests are usually more expensive than other biochemical tests and it is therefore important that they are used prudently. Apart from financial considerations, inappropriate use of tumour marker results can lead to unnecessary investigations with attendant risks to patients. The purpose of this review is to outline the recommended clinical applications of the most commonly requested tumour markers to enhance effective utilisation of the same.

Classification of tumour markers: There are two main types of tumour markers; Tumour associated antigens or cellular tumour markers, and humoral tumour markers which are detected in body fluids $(2,3)$. This review focuses on humoral tumour markers. Tumour markers can be classified according to the structure or biological function of the molecule (Table 1). 
Table 1

Classification of tumour markers

\begin{tabular}{|c|c|}
\hline Biochemical class & Example \\
\hline Enzymes & $\begin{array}{l}\text { Alkaline phosphatase } \\
\text { Prostatic acid phosphatase } \\
\text { Prostate specific antigen (PSA) }\end{array}$ \\
\hline Hormones & $\begin{array}{l}\text { ACTH } \\
\text { Calcitonin } \\
\text { Growth hormone } \\
\text { HCG } \\
\text { Prolactin }\end{array}$ \\
\hline Proteins & $\begin{array}{l}\text { Immunoglobulins } \\
\beta 2-\text { Microglobulin } \\
\text { C- peptide } \\
\text { Ferritin }\end{array}$ \\
\hline Oncofetal proteins & $\begin{array}{l}\alpha-\text { fetoprotein } \\
\text { CEA } \\
\text { Squamous cell carcinoma antigen (SCC) } \\
\text { Tissue polypeptide antigen (TPA) }\end{array}$ \\
\hline Carbohydrate epitopes & $\begin{array}{l}\text { CA } 125 \\
\text { CA15.3 } \\
\text { CA19.9 }\end{array}$ \\
\hline $\begin{array}{l}\text { Receptors } \\
\text { Oncogene products }\end{array}$ & $\begin{array}{l}\text { Oestrogen/progesterone receptors } \\
\text { c-myc translocation } \\
\text { c-erb B2 amplification (HER-2) } \\
\text { bcl-2 }\end{array}$ \\
\hline
\end{tabular}

Clinical uses of tumour markers: Tumour markers can be used to determine risk of cancer, screen for early cancer, establish diagnosis, estimate prognosis, predict that a specific therapy will work, or monitor for disease recurrence or progression (1-3).

The sensitivity and specificity of tumour markers determine the clinical usefulness of markers for each of these applications. Theideal tumour marker would be highly specific for a particular cancer and highly sensitive for the required application (1-3). A tumour marker may therefore be suitable for treatment monitoring but not useful for screening or primary diagnosis of the tumour.

Screening: The concept of screening involves evaluation of apparently healthy individuals to detect early or occult disease. Screening for cancer is useful if the malignancy is prevalent and there are effective therapeutic interventions for early disease. Most tumour markers have inadequate specificity and sensitivity profiles for effective use in cancer screening especially in populations with low prevalence for the particular cancer (1-3). In spite of this, studies show that tumour markers are increasingly used to screen for cancer in the clinical setting $(1,3-6)$.
Primary diagnosis: Ideally, a tumour marker needs to be $100 \%$ sensitive and $100 \%$ specific to be useful for definitive diagnosis of cancer. Apart from Human Chorionic Gonadotropin (HCG) in choricarcinoma, few other markers are ideal for this application and thus not recommended for this use $(2,3)$.

Prognosis: The tumour burden at the time of presentation is one of the determinants of prognosis in cancer. If a tumour marker concentration is related to the tumour size then it may be useful for prognostication. HCG and AFP is used for prognosis in patients with testicular teratoma, while PSA has prognostic value in prostate cancer $(2,3)$.

Treatment monitoring detection of relapse: The most effective clinical use of tumour markers is in determining treatment efficacy and detecting tumour recurrence (1-3). This application requires serial estimation of a sensitive tumour marker, starting before any intervention is administered. The analytical aspects of the tumour marker are important in interpreting concentrations of tumour markers in this application. The same analytical technique should be used in serial marker testing and any change in 
analytical methodology communicated to clinicians to enable proper interpretation of results (1). Ideally, interpretative comments of elevated tumour marker reports should be given by laboratories estimating tumour markers.

The treatment response may be judged depending on the marker as:

(i) No change - tumour marker does not fall to less than $50 \%$ of the pre-treatment concentration;

(ii) Improvement - tumour marker falls to less than $50 \%$ of pre-treatment concentration;

(iii) Response - tumour marker falls to less than $10 \%$ of pre-treatment concentration;

(iii) Complete response - tumour marker falls to non-malignancy reference values.

The degree of reduction that indicates significant change may however differ depending on the specific tumour marker. Serial tumour marker estimation following treatment can be used to detect relapse. Biochemical relapse may precede radiological or clinical relapse by several months to years (1-3).

\section{SPECIFIC TUMOUR MARKERS AND THEIR USES}

Carcinoembryonic antigen (CEA): CEA is an oncofetal antigen first discovered in extracts of colonic adenocarcinomas in 1965. It is a glycoprotein which appears to have a role in cell adhesion (1-3).

Its main clinical application is in management of colorectal carcinoma. CEAmay however also beuseful in several mucinous adenocarcinomas, particularly gastrointestinal, ovarian and breast $(1,2)$.

Several non neoplastic conditions are associated with CEA elevation including cigarette smoking, hepatitis, alcoholic liver disease, ulcerative colitis, Crohn's disease and pancreatitis. The serum reference range is $0-3.5 \mathrm{ng} / \mathrm{ml}$ in adult non smokers and 0 $-5.0 \mathrm{ng} / \mathrm{ml}$ in adult smokers $(1,2)$.

\section{APPLICATIONS OF CEA IN COLORECTAL CANCER}

Screening: CEA is not recommended for colorectal cancer screening $(1,5,6,7)$. The limitations for this application include the low prevalence of colorectal cancer in healthy populations, the low specificity of CEA for colorectal cancer and low sensitivity of CEA for early cancer (6-10). Screening aims at detecting early curable disease but significant CEA elevation normally occurs in advanced disease $(9,10)$.

Prognosis in colorectal cancer: Preoperative CEA values correlate positively with disease stage and negatively correlated with disease free survival thus having prognostic value in colorectal cancer patients (11). The histological differentiation however influences the elaboration of CEA; high values found in well differentiated adenocarcinomas while poorly differentiated tumours may have negative values. This limits the use of CEA in prognostication. Pre-treatment estimation of CEA is however recommended for newly diagnosed patients to guide therapeutic interventions as well as form a baseline for follow-up (9-11).

Treatment monitoring: This is the commonest application of CEA. Following surgery, CEA returns to normal within one to two months. If CEA remains elevated it may indicate residual disease (12-14). During follow-up of patients receiving surgical or systemic therapy, CEA should be measured every three months for at least three years after diagnosis (15). Significant CEA elevation during monitoring is considered as an increase at least 30\% above the previous value which is confirmed by a third sample measured within one month. Persistent mild elevations are also important indicators of disease progression $(14,15)$.

Detection of relapse: Serial estimation of CEA can be used to monitor disease recurrence. CEA can precede clinical relapse by several months. A second look operation with intention for curative resection is recommended if there is a significant rise of CEA above a base line level on serial determination $(8,9)$.

Alpha-fetoprotein (AFP): AFP is a normal foetal serum glycoprotein synthesized by the liver, yolk sac, and gastrointestinal tract that is homologous to albumin. AFP is elevated in the circulation of newborns but the levels decline over the next 12 months to 10-20 $\mathrm{ug} / \mathrm{L}(2,4,16)$

AFP is used in management of patients with hepatocellular carcinoma, hepatoblastoma in children and non-seminomatous germ cell tumours. Non neoplastic conditions that are associated with AFP elevation include hepatitis, cirrhosis, biliary obstruction, alcoholic liver disease $(1,16)$. Physiological elevation of AFP is found in pregnancy and infants.

\section{APPLICATION OF AFP IN HEPATOCELLULAR CARCINOMA}

Screening: The rationale behind screening for hepatocellular carcinoma (HCC) in asymptomatic individuals groups is to identify early potentially curable tumours. This is only cost effective if it is done among high risk populations. Screening is therefore recommended in patients with hepatic cirrhosis of any aetiology $(17,18)$. There is also some support for screening hepatitis B surface antigen positive individuals with active chronic hepatitis $(9,19)$. Frequency of AFP estimation in screening is twice a year combined with liver ultrasound (20). 
Diagnosis of hepatocellular carcinoma: Although elevation of AFP even upto 1,000 ug / L may occur in patients with hepatitis or liver cirrhosis, the proportion of patients with HCC having raised AFP levels ranges from $70-90 \%$, making it useful for diagnosis $(9,18,19)$. The decision limit for discrimination between HCC and chronic liver disease is usually between 400 and $500 \mathrm{ug} / \mathrm{L}(9,19)$. There should however be suspicion for HCC in patients with AFP values more than $20 \mathrm{ug} / \mathrm{L}$ particularly those with steadily rising values. It is recommended that such patients should be followed up closely using imaging techniques.

Prognosis: There is evidence showing that elevation of AFP in HCCindicates poor prognosis when compared with normal AFP HCC cases. Patients with AFP elevation have been found to have more aggressive tumours. The pre-treatment AFP concentration correlates with patient survival so that those with AFP values above $1000 \mathrm{ug} / \mathrm{L}$ have shorter survival than patients with AFP values less than $200 \mathrm{ug} / \mathrm{L}$ (21). The AFP doubling time may also be used as a prognostic determinant.

Treatment monitoring: Serial AFP determinations can be used to monitor completeness of surgical resection or effectiveness of systemic treatment of HCC in patients with increased pre-treatment AFP levels. After complete surgical complete removal of the tumour or following chemotherapy, AFP levels should decrease rapidly. Delayed clearance of AFP indicating a long AFPhalf-life would be suggestive of incomplete tumour resection or progressive disease, while failure of the AFP to normalise implies residual malignancy $(22,23)$.

Prostate specific antigen: Prostate specific antigen (PSA) is a serine protease belonging to the glandular kallikrein family. The physiological role of PSA is in the liquefaction of semen $(1,2,16)$. PSA circulates either as a free molecule (free PSA) or complexed with protease inhibitors $(2,16)$. Its main use is in management of prostate cancer.

Other causes of PSA elevation include benign prostatic hyperplasia, prostatitis, urine retention, transurethral resection of prostate, prostate biopsy, prostate massage (16).

\section{USE OF PSA IN PROSTATE CANCER}

Screening: There is still debate on whether population screening for prostate cancer is cost-effective (2426). In spite of this PSA remains the most requested for tumour marker in cancer screening (1). In the USA annual PSA estimation is recommended for cancer screening together with digital rectal examination, in males above 50 years of age. Follow up is recommended for those with PSA above $4 \mathrm{ug} / \mathrm{L}$ $(26,27)$. In high risk individuals such as African men and those with first degree relatives having prostate cancer, screening can begin from 40 - 45 years (27).

Although PSA is prostate specific, it is not cancer specific and elevations can occur in benign prostatic hyperplasia and prostatitis (16). To avoid unnecessary biopsies in individuals with mild PSA elevation, use of age specific reference values and estimation of proportion of free PSA ratio have been recommended, among other strategies (28). Individuals with benign disease have higher percent free PSA than those with cancer. Because prostate manipulations can elevatePSAblood should be drawn prior to such interventions or delayed by several days if manipulations have been done. Following prostate surgery estimation of PSA should be delayed by upto six weeks (29).

Treatment monitoring: Serial total PSA estimation plays an important role in management of prostate cancer including surveillance, selection of optimal treatment regimens, determination of prognosis and post-therapeutic monitoring. The pre-treatment PSA values correlate with disease stage and prognosis, extra glandular spread usually being present in patients with PSA values above $50 \mathrm{ug} / \mathrm{L}$ (30). The PSA doubling time is also an important predictor of metastatic disease. Following successful surgery, PSA should decrease to undetectable levels and persistent elevation is suggestive of residual disease $(30,31)$. Undetectable PSA in post-operative period is however not always indicative of surgical cure. A rising PSA level after radical prostatectomy is in keeping with recurrent disease and may predate other clinical signs of progression by several years (30-33). Such biochemical recurrence is defined as three consecutive rises in PSA above the nadir.

CA125: CA125 is a glycoprotein originally developed through the production of a monoclonal antibody OC 125 by immunising mice with cells from an ovarian carcinoma cell line $(1,2,16)$. Its physiological function has not been established.

The main clinical utility is in epithelial ovarian carcinoma. There are other malignancies which are associated with CA 125 elevation including intraabdominal and pelvic carcinomas such as colorectal, gastric, pancreatic, endometrial. CA 125 should not however be used in non-ovarian tumours and so it should not be measured in males $(1,16)$.

Non-neoplastic conditions associated with elevated CA 125 include endometriosis, ascitis, pancreatitis, pelvicinflammatory disease, peritonitis, menstruation and pregnancy $(1,16)$. 


\section{CLINICAL APPLICATION OF CA 125 IN OVARIAN CARCINOMA}

Screening and early detection of ovarian cancer: CA 125 is not recommended for screening asymptomatic women $(1,16,34,35)$. It can be applied, together with pelvic evaluation in targeted screening of women with history of hereditary ovarian cancer (35). CA 125 is useful in evaluation of postmenopausal women with pelvic or ovarian masses. A cut-off of $95 \mathrm{U} / \mathrm{mL}$ is recommended for distinguishing benign from malignant masses (16). This application is limited in pre-menopausal women because of the numerous benign conditions associated with CA 125 elevation.

Prognosis: The pre- and post-operative CA 125 levels have prognostic significance in cancer of ovary and CA 125 is recommended for this application (35-37). Persistent elevation of CA 125 after surgery and after three cycles of chemotherapy indicate poor prognosis. Studies have shown that patients with pre-operative CA 125 above $65 \mathrm{U} / \mathrm{mL}$ and those with CA125 halflife more than 20 days have low five year survival rates $(38,39)$.

Treatment monitoring: Postoperative serial monitoring of CA 125 levels is useful for detecting residual disease and relapse hence determining need for chemotherapy (40). CA 125 above 35U/mL after surgery usually indicates presence of residual disease. It is recommended that CA 125 estimations are done every two to four months, according to the clinical follow-up visits for two yearsinitially if pre-treatment levels were high. Elevated CA 125 in post operative follow-up may precede clinical relapse by two to six months (38-40).

Serial estimation of CA 125 also has a role in monitoring chemotherapy (40). Aresponse is defined as reduction of $50 \%$ or more from pre-treatment CA 125 level. This reduction should be sustained for at least 28 days $(36,40)$. The pre-treatment sample should be taken within two weeks of initiating chemotherapy and subsequent samples taken at intervals of 2-4 weeks during treatment, and 2-3 weeks during followup (40).

CA19.9: CA 19.9 is a mucin antigen related to the Lewis blood group which may functionally be involved in cell adhesion (16).
The main use of CA 19.9 is in pancreatic adenocarcinoma $(1,16)$. Other possible uses include gastric and colorectal carcinomas. It is not recommended for non GIT malignancies. Non neoplastic causes of CA 19.9 elevations include pancreatitis, hepatitis, cirrhosis and cholangitis $(1,16)$.

\section{USES OF CA 19.9 IN PANCREATIC ADENOCARCINOMA}

Screening: Population screening for pancreatic cancer is not recommended because of the low prevalence of the tumour. Even among high risk individuals, screening using CA 19.9 is not recommended since the tumour marker is not significantly elevated until the lesions are invasive $(41,42)$.

Primary diagnosis: CA19.9isnotusually recommended for diagnosis of pancreatic carcinoma. It may however have a limited role in diagnosis if used together with imaging studies $(9,43,44)$. The limitations are as a result of inadequate sensitivity and specificity profiles in early disease using the recommended cut-off value of $37 \mathrm{U} / \mathrm{ml}$. The specificity increases significantly if the cut-off is raised approaching $100 \%$ for CA 19.9 levels more than $1000 \mathrm{U} / \mathrm{mL}$ which is however commensurate with advanced disease (45). Elevation of CA 19.9 in non neoplastic hepatobiliary diseases including biliary obstruction cholangitis and cirrhosis also contributes to the inadequacy of the marker for diagnosis $(1,16)$.

Prognosis and treatment monitoring: Serum CA 19.9 levels at diagnosis is an indicator for tumour resectablility, effectiveness of chemotherapy and patient survival. Response of CA 19.9 to treatment can also be useful for stratification. Patients whose CA 19.9 levels returned to normal after surgical resection survive longer than those whose CA 19.9 do not normalise $(9,45-48)$.

The main application for CA 19.9 in pancreatic adenocarcinoma is in treatment monitoring. SerialCA 19.9 measurements can be used, together withimaging studies to assess efficacy of treatment particularly in patients receiving palliative chemotherapy. Reduction of CA 19.9 greater than $20 \%$ of baseline value usually indicates adequate response to the treatment regimen (49).

A summary of the main tumour markers and their recommended applications (Table 2). 
Table 2

Summary of common tumour markers applications

\begin{tabular}{|c|c|c|c|c|}
\hline Marker & $\begin{array}{l}\text { Reference } \\
\text { Range }\end{array}$ & $\begin{array}{l}\text { Main malignancy } \\
\text { and uses }\end{array}$ & $\begin{array}{l}\text { Other malignancies } \\
\text { with raised values }\end{array}$ & $\begin{array}{l}\text { Non neoplastic } \\
\text { causes of } \\
\text { raised levels }\end{array}$ \\
\hline CEA & $\begin{array}{l}\text { Non smokers: } \\
\text { 0-3.5ug/L } \\
\text { Smokers: } \\
\text { 0-5ug/L }\end{array}$ & $\begin{array}{l}\text { Colorectal } \\
\text { carcinoma: } \\
\text { P, TM, R }\end{array}$ & $\begin{array}{l}\text { Other } \\
\text { gastrointestinal } \\
\text { malignancies, } \\
\text { breast and ovarian } \\
\text { carcinoma }\end{array}$ & $\begin{array}{l}\text { Hepatitis, } \\
\text { cirrhosis, } \\
\text { biliary } \\
\text { obstruction, } \\
\text { Crohn's disease, } \\
\text { bronchitis. }\end{array}$ \\
\hline AFP & $0-10 \mathrm{U} / \mathrm{L}$ & $\begin{array}{l}\text { Hepatocellular } \\
\text { carcinoma } \\
(\mathrm{S}, \mathrm{D}, \mathrm{TM}) \\
\text { Hepatoblastoma (D) } \\
\text { Non-semitomatous } \\
\text { germ cell tumours } \\
(\mathrm{P}, \mathrm{TM})\end{array}$ & $\begin{array}{l}\text { Not recommended } \\
\text { for other tumours }\end{array}$ & $\begin{array}{l}\text { Hepatitis, } \\
\text { cirrhosis, } \\
\text { biliary } \\
\text { obstruction }\end{array}$ \\
\hline PSA & $0-4 \mathrm{ug} / \mathrm{L}$ & $\begin{array}{l}\text { Prostate cancer } \\
(\mathrm{S}, \mathrm{D}, \mathrm{P}, \mathrm{TM})\end{array}$ & $\begin{array}{l}\text { Not recommended } \\
\text { for other tumours }\end{array}$ & $\begin{array}{l}\text { Benign } \\
\text { prostate } \\
\text { hyperplasia, } \\
\text { prostatitis }\end{array}$ \\
\hline CA 125 & $0-35 \mathrm{U} / \mathrm{L}$ & Ovarian cancer & $\begin{array}{l}\text { Not recommended } \\
\text { in males or for non- } \\
\text { ovarian cancers }\end{array}$ & $\begin{array}{l}\text { Endometriosis, } \\
\text { peritonitis, } \\
\text { ascites, pelvic } \\
\text { inflammatory } \\
\text { disease }\end{array}$ \\
\hline CA 19.9 & $0-37 \mathrm{U} / \mathrm{L}$ & Pancreatic cancer & $\begin{array}{l}\text { Gastric, colorectal and } \\
\text { cholangiocarcinoma }\end{array}$ & $\begin{array}{l}\text { Pancreatitis, } \\
\text { cholangitis, } \\
\text { hepatitis, } \\
\text { cirrhosis. }\end{array}$ \\
\hline
\end{tabular}

$\mathrm{S}=$ Screening, $\mathrm{D}=$ Diagnosis, $\mathrm{P}=$ Prognosis, $\mathrm{TM}=$ Treatment monitoring

\section{CONCLUSION}

There are several markers which can aid in the management of patients with cancer. An evidence based approach is needed to ensure that these markers are used cost-effectively. If not used judiciously, tumour markers increase the cost of patient care unnecessarily and may be harmful to patients. The use of tumour marker "panels" is particularly discouraged because of the non-specific nature of most tumour markers.

\section{REFERENCES}

1. Sturgeon, C. M., Lai, L.C. and Duffy, M.J. Clinical review serum tumour markers: how to order and interpret them. Br. Med. J. 339: B3527.

2. Roulston, J.E. and Leonard, R.F.C. Serological tumour marker. An introduction. Churchill Livingstone. 1993.

3. Schrohl, A.S., Holten-Andersen, M., Sweep, F., et al. Tumour markers review. Molecular Cellular Proteomics. 2003; 2: 378-387.

4. Ntaios, G., Hatzitolios, A., Chatzinikolaou, A., et al. An audit of tumour marker utilization in Greece. Eur. J. Intern. Med. 2009; 20: 6-9. 
5. McGinley, P.J. and Kilpatrick, E.S. Tumour markers: their use and misuse by clinicians. Ann. Clin. Biochem . 2003; 40: 643-647.

6. Kilpatrick, E.S. and Lind, M.J.Appropriate requesting of serum tumour markers. Br. Med. J. 2009; 339: b3111.

7. Duffy, M.J. CEA as a marker for colorectal cancer: is it clinically useful? Clin. Chem. 2001; 47: 624-630.

8. Bast, R.C., Ravdin, P., Hayes, D.F., et al. 2000 Update of recommendations for the use of tumor markers in breast and colorectal cancer: clinical practice guidelines of the American Society of Clinical Oncology. J. Clin. Oncol. 2001; 19: 1865-1878.

9. Klapdor, R., Aronsson, A.C., Duffy, M.J., et al. Tumor markers in gastrointestinal cancers: EGTM recommendations. Anticancer. Res. 1999; 119: 2811-2815.

10. Duffy, M.J., van Dalen, A., Haglund, C., et al. Clinical utility of biochemical markers in colorectal cancer: European Group on Tumour Markers (EGTM) guidelines. Eur. J. Cancer. 2003; 39:718-727.

11. Compton, C.C., Fielding, L.P., Burgart, L.J., et al. Prognostic factors in colorectal cancer. Arch. Pathol. Lab. Med. 2000; 124: 979-994.

12. Rosen, M., Chan, L., Beart, R.W., Vukasin, P. and Anthone, G. Follow-up of colorectal cancer: a meta analysis. Dis. Colon. Rectum. 1998; 41: 1116-1126.

13. Renehan, A.G., Egger, M., Saunders, M.P. and O'Dwyer, S.T. Impact on survival of intensive follow up after curative resection for colorectal cancer: systematic review and meta-analysis of randomised trials. Br. Med. J. 2002; 324: 813-816.

14. Figueredo, A., Rumble, R.B., Maroun, J., et al. Followup of patients with curatively resected colorectal cancer: a practice guideline. BMC Cancer. 2003; 3: 26-39.

15. Desch, C.E., Benson III, A.B., Somerfield, M.R., et al. Colorectal cancer surveillance: 2005 update of an American Society of Clinical Oncology practice guideline. J. Clin. Oncol. 2005; 23: 8512-8519.

16. Duffy, M.J., McGing, P. and McSweeney, J. Guidelines for the use of tumour markers. ACBI. 2nd Ed. 2000.

17. Gebo, K.A., Chander, G., Jenckes, M.W., et al.Screening tests for hepatocellular carcinoma in patients with chronic hepatitis C: a systematic review. Hepatology. 2002; 36: S84-S92.

18. Bruix, J., Sherman, M., Llovet, J.M., et al. Clinical management of hepatocellularcarcinoma:conclusions of the Barcelona-2000 EASL Conference. J. Hepatol. 2001; 35: 421-430.

19. Ryder, S.D. Guidelines for the diagnosis and treatment of hepatocellular carcinoma (HCC) in adults. Gut. 2003; 52: 1-8.

20. Ngueyen, M.H. and Keeffe, E.B. Screening for hepatocellular carcinoma.J. Clin. Gastroenterol. 2002;35 S2: S86-S91.

21. Johnson, P.J., Melia, W.M., Palerm, M.K., Protman, B. and Williams, R. Relationship between serum alphafetoprotein, cirrhosis, and survival in hepatocellular carcinoma. Br. J. Cancer. 1981; 44: 502-505.

22. Tangkijvanich, P., Anukulkarnkusol, N., Suwangool, P., et al. Clinical characteristics and prognosis of hepatocellular carcinoma: analysis based on serum alpha-fetoprotein levels. J. Clin. Gastroenterol. 2000; 31: 302-308.

23. Matsumoto, Y., Suzuki, T., Ono, H., et al. Response of alpha-fetoprotein to chemotherapy in patients with hepatoma. Cancer. 1974;34:1602-1606.

24. Sturgeon, C. Practice guidelines for tumor marker use in the clinic. Clin. Chem. 2002; 48: 1151-1159.

25. Zoorob, R., Anderson, R., Cefalu, C. and Sidani, M. Cancer screening guidelines. Am. Fam. Physician. 2001; 63: 1101-1112.

26. Harris, R. and Lohr, K.N. Screening for prostate cancer: an update of the evidence for the U.S. Preventive Services Task Force. Ann. Intern. Med. 2002; 137: 917-929.

27. Smith, R.A., Cokkinides, V. and Eyre, H.J. American Cancer Society Guidelines for the early detection of cancer, 2005. CA. Cancer. J. Clin. 2005; 55: 31-44.

28. Catalona, W.J., Partin, A.W., Finlay, J.A., et al. Use of percentage of free prostate-specific antigen toidentify men at high risk of prostate cancer when PSA levels are 2.51 to $4 \mathrm{ng} / \mathrm{mL}$ and digital rectal examination is not suspicious for prostate cancer: an alternative model. Urology. 1999; 54: 220-224.

29. Oberpenning, F., Schmid, H.P., Fuchs-Surdel, W., et al. The impact of intraoperative manipulation of the prostate on total and free prostate-specific antigen. Int. J. Biol. Markers. 2002; 17:154-160.

30. Semjonow, A. and Schmid, H.P. The rise and fall of PSA: clinical implications of prostate specific antigen kinetics. Urol. Res. 2002; 30: 85-88.

31. Pontes, J.E., Jabalameli, P., Montie, J., et al. Prognostic implications of disappearance rate of biologic markers following radical prostatectomy. Urology. 1990; 36: 415-419.

32. Amling, C.L., Bergstralh, E.J., Blute,M.J., et al. Defining prostate-specific antigen progression after radical prostatectomy: What is the appropriate cutpoint? J. Urol. 2001;165: 1146-1151.

33. Pound, C.R., Partin, A.W., Eisenberger, M.A., et al. Natural history of progression after PSA elevation following radical prostatectomy. JAMA. 1999; 281: 1591-1597.

34. American College of Physicians. Clinical Guideline: Screening for Ovarian Cancer: Recommendations and Rationale. Ann. Intern. Med. 1994; 121:141-142.

35. NIH consensus conference. Ovarian cancer. Screening, treatment, and follow-up. NIH consensus development conference. JAMA. 1995; 273: 491-497.

36. Cooper, B.C.,Sood, A.K., Davis, C.S., et al. Preoperative CA125 levels: An independent prognostic factor for epithelial ovarian cancer. Obstet. Gynecol. 2002; 100: 59-64.

37. Rustin, G.J. The clinical value of tumour markers in the management of ovarian cancer. Ann. Clin. Biochem. 1996; 33: 284-289.

38. Meyer, T. and Rustin, G.J. Role of tumour markers in monitoring epithelial ovarian cancer. Br. J. Cancer. 2000; 82: 1535-1538.

39. Verheijen, R.H., von Mensdorff-Pouilly, S., van Kamp, G.J. and Kenemans, P. CA125: fundamental and clinical aspects. Semin. Cancer. Biol. 1999; 9: 117-124.

40. Fritsche,H.A. and Bast, R.C.CA125 in ovarian cancer: advances and controversy. Clin. Chem. 1998; 44: 13791380. 
41. Kim, J.E., Lee, K.T., Lee, J.K., et al. Clinical usefulness of carbohydrate antigen 19-9 as a screening test for pancreatic cancer in an asymptomatic population. J. Gastroenterol. Hepatol. 2004;19:182-186.

42. Canto, M.I.G.M., Yeo, C.J., Griffin, C., et al. Screening for pancreatic neoplasia in high riskindividuals. Clin. Gastro. Hepatol. 2003; 2: 606-621.

43. Steinberg, W. The clinical utility of the CA 19-9 tumor-associated antigen. Am. J. Gastroenterol. 1990; 85: 350-355

44. Ritts, R.E. and Pitt, H.A. CA19-9 in pancreatic cancer. Surg. Oncol. Clin. N. Am. 1998; 7: 93-101.

45. Schlieman, M.G., Ho, H.S. and Bold, R.J. Utility of tumor markers in determining resectability of pancreatic cancer. Arch. Surg. 2003; 138: 951-956.

46. Forsmark, C.E., Lambiase, L. and Vogel, S.B. Diagnosis of pancreatic cancer and prediction of unresectability using the tumor-associated antigen CA19-9. Pancreas. 1994; 9: 731-734.

47. Grem,J. The prognostic importance of tumor markers in adenocarcinomas of the gastrointestinal tract. Curr. Opin. Oncol. 1997; 9: 380-387.

48. Montgomery, R.C., Hoffman, J.P., Riley, L.B., et al. Prediction of recurrence and survival by post-resection CA 19-9 values in patients with adenocarcinoma of the pancreas. Ann. Surg. Oncol. 1997; 4: 551-556.

49. Gogas, H., Lofts, F.J., Evans, T.R., Daryanani, S. and Mansi, J.L. Are serial measurements of CA19-9 useful in predicting response to chemotherapy in patients with inoperable adenocarcinoma of the pancreas? $\mathrm{Br}$. J. Cancer. 1998; 77: 325-328. 